\title{
Impact of Canopy Cover on Butterfly Abundance and Diversity in Intermediate Zone Forest of Sri Lanka
}

\author{
B.M.B. Weerakoon ${ }^{* 1}$, A.M.R.S. Bandara ${ }^{2}$ and K.B. Ranawana ${ }^{3}$ \\ ${ }^{1}$ Post Graduate Institute of Science, University of Peradeniya, Sri Lanka \\ ${ }^{2}$ ScienceEducation Unit, Faculty of Science, University of Peradeniya, Sri Lanka \\ ${ }^{3}$ Department of Zoology, Faculty of Science, University of Peradeniya, Sri Lanka
}

Date Received: 30-12-2014 Date Accepted: 14-05-2015

\begin{abstract}
This study was designed to identify the influence of canopy cover on butterfly abundance in young secondary forest and regenerating forest at Maragamuwa area of Kumaragala forest reserve in Naula, Matale district of Sri Lanka. Line transect method was used to collect data. Hundred meter long five transects were established in each forest area. Butterfly abundance data were collected weekly for eight months from January to August 2014. Regenerating forest had low canopy cover $(<50 \%)$ than young secondary forest (20-90\%). Total of 2,696 butterflies belonging to 87 species in six families were recorded. Some butterfly species were restricted to shady areas, but most butterflies were abundant in sunny areas. Butterflies in some families (Family Lycanidae, Nymphalidae, Pieridae) were abundant in sunny conditions and some families (Family Hesperiidae, Papilionidae) abundant in shade. ANOVA was conducted to identify the variation of number of species $(\mathrm{F}=54.05, \mathrm{p}<0.001)$ and among abundance $(\mathrm{F}=10.49, \mathrm{p}<0.05)$ with the canopy cover. Species richness was high in moderate canopy cover $(20 \pm 5 \%)$. Negative Pearson correlation coefficient stated butterfly abundance decreased with the canopy cover $(r=-0.91)$ and species richness decreased with canopy cover $(r=-0.85)$.

Some butterflies were common in sunny areas and some species were confined to shady areas. However, most of the species were generally found throughout the area. Regenerating forest encountered more shrubs than in young secondary forest, which butterflies preferred to food on. Main findings of the study were that butterfly abundance was high in sunny areas and butterfly species richness was high in moderate shady areas.
\end{abstract}

Keywords: canopy cover, understory, young secondary forest, regenerating forest

\section{Introduction}

Canopy is the primary barrier on preventing light penetration to forest floor. Through the forest succession, canopy cover influence beneath forest vegetation. Hence, canopy affects the species heterogeneity of the forest vegetation. Thick canopy cover causes reduced understory which dominate by shrubs and herbs. These shrubs and herbs are rich in flowers which serve as a good food source for nectar feeding organisms such as bees and butterflies. Butterflies are an important insect group in plant

*Correspondence: buddhikavray@gmail.com

Tel: +94713391713

ISSN 2235-9370 Print/ISSN 2235-9362 Online @ U University of Sri Jayewardenepura 
pollination. The mutually benefited relationship among plants and butterflies is important in plant reproduction. Plants get pollinated while butterfly gets nectar. Therefore, butterflies attract to nectar sources around their range.

Logging and forest fires are the main threats that influence depletion of canopy cover. Unlogged forests have significantly large trees, forest density, tree sizes and greater canopy cover compared to logged forests (Hill, 1999). Through the succession process of a logged forest to a mature secondary forest, different types of vegetation structures dominate. This variation and habitat heterogeneity increases the quality of the habitat. Moreover, quality of a particular habitat depends on the number of species utilising it.

Disturbance to canopy cover changes the habitat quality. Canopy gaps influence the understory growth of those areas. As other organisms, butterfly species richness and composition is affected by the habitat quality (Collinge et al., 2003). Undisturbed canopy has recorded high butterfly abundance and diversity (Addai and Baidoo, 2013). Unlogged forests have significantly high butterfly species richness, abundance, evenness and index of taxonomic distinctiveness (Hill et al., 1995). Some butterfly species prefer sunny conditions while some others prefer shady conditions. Most butterflies which prefer sunny conditions are habitat generalists. They are abundant throughout a wide geographic range. Shade preferring butterflies are habitat specialists and have a narrow geographic range. Those habitat specialists are mostly confined to climax forests and adversely affected by forest logging (Spitzer et al., 1993; Hamer et al., 2003; Malabika, 2011). Hence, there may be a difference in butterfly abundance and diversity under different shade levels. Main objective of this study was to identify the impact of canopy cover on butterfly abundance and diversity.

\section{Methodology}

The study was conducted in young secondary forest $\left(7^{\circ} 41^{\prime} 57^{\prime /} \mathrm{N}, 80^{\circ} 42^{\prime} 26^{\prime \prime} \mathrm{E}\right)$ and adjoining regenerating forest $\left(7^{\circ} 41^{\prime} 47^{\prime /} \mathrm{N}, 80^{\circ} 42^{\prime} 34^{\prime /} \mathrm{E}\right)$ in Maragamuwa area within Kumaragala forest reserve in Naula area in Matale district in Sri Lanka. The forest reserve is under the preview of the Forest Department of Sri Lanka. Vegetation structure of the 30 year old young secondary forest was much mature than the structure of ten year old regenerating forest. Young secondary forest consists with few emergent tree species, thick canopy and sub canopy cover, relatively low understory and ground layer. Generally ground is covered with dead leaves and fallen branches. But the regenerating forest consists of low canopy cover with short trees, rich understory and ground layer. Understory mainly dominates by shrubs and herbs, and ground layer is covered with grass species.

Hundred meters long line transects were used to collect butterfly abundance data. Five transects were established in regenerating forest and five transects in young secondary forest. Twenty minutes were spent in each transect. All butterfly species and their abundance was recorded up to five meters distance on both left and right from transect. Butterflies were identified according to d' Abrera (1998) and Banks and Banks (2014). Canopy cover in each observation was recorded and it was measured by hemispherical densiometer. Data were collected once a week for eight months from January to August 2014 spending morning hours to collect data. One way ANOVA was carried out to identify the variation of species richness and abundance with canopy cover. Pearson correlation coefficient was used to identify the relationships among species richness and abundance with the canopy cover using MINITAB 14 software. Relative abundance of butterflies in each family at different canopy cover levels was also calculated. 


\section{Results}

Total of 2,696 butterflies of 87 species belonged to six families were recorded during the study. Of the 87 species recorded, most species belong to family Nymphalidae $(n=28)$ followed by family Lycanidae $(n=20)$. Least species were belonged to family Riodinidae $(n=1)$. Regenerating forest had less canopy cover $(<50 \%)$ compared to young secondary forest $(20-90 \%)$. Canopy in the young secondary forest is more constantly connected with few canopy gaps. However, canopy in regenerating forest is poorly spread and there were more canopy gaps than canopy cover. More individuals and species were recorded at low canopy area, while less abundance and number of species were observed

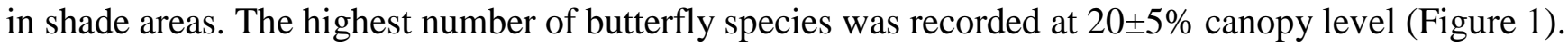
Highest butterfly abundance recorded at 10\% canopy cover (Figure 2). Individuals of more light preferring butterflies were recorded in these areas.

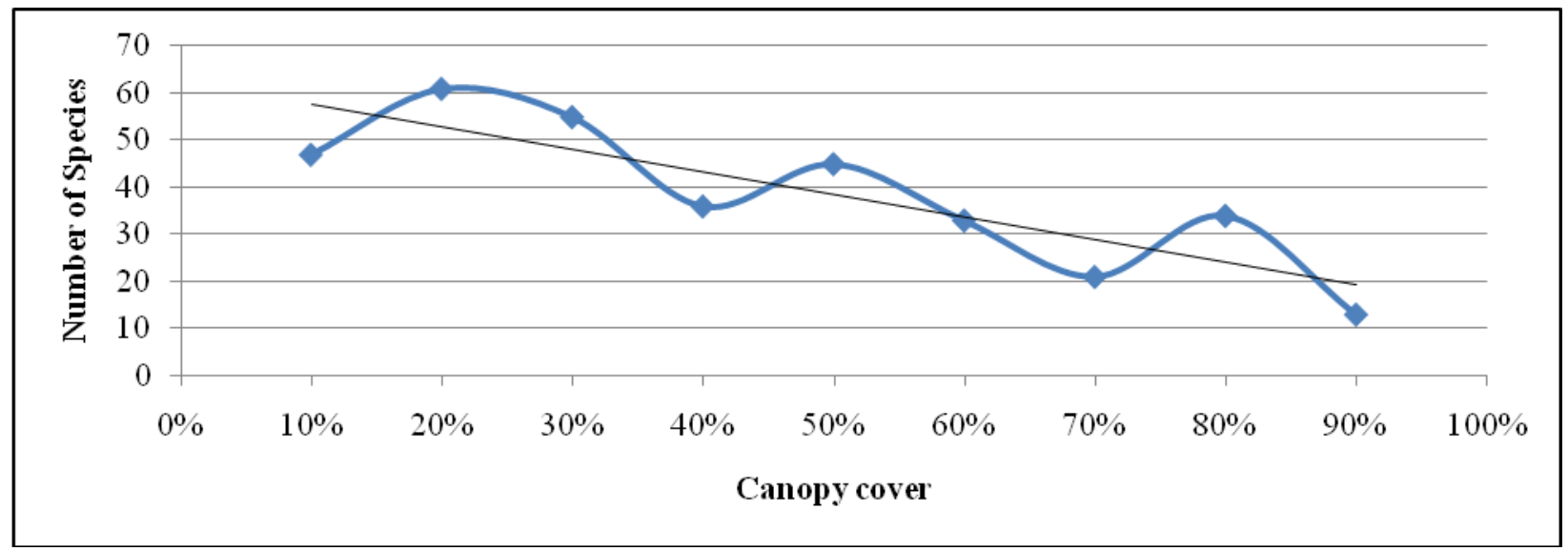

Figure 1: Distribution of recorded number of species with percent canopy cover.

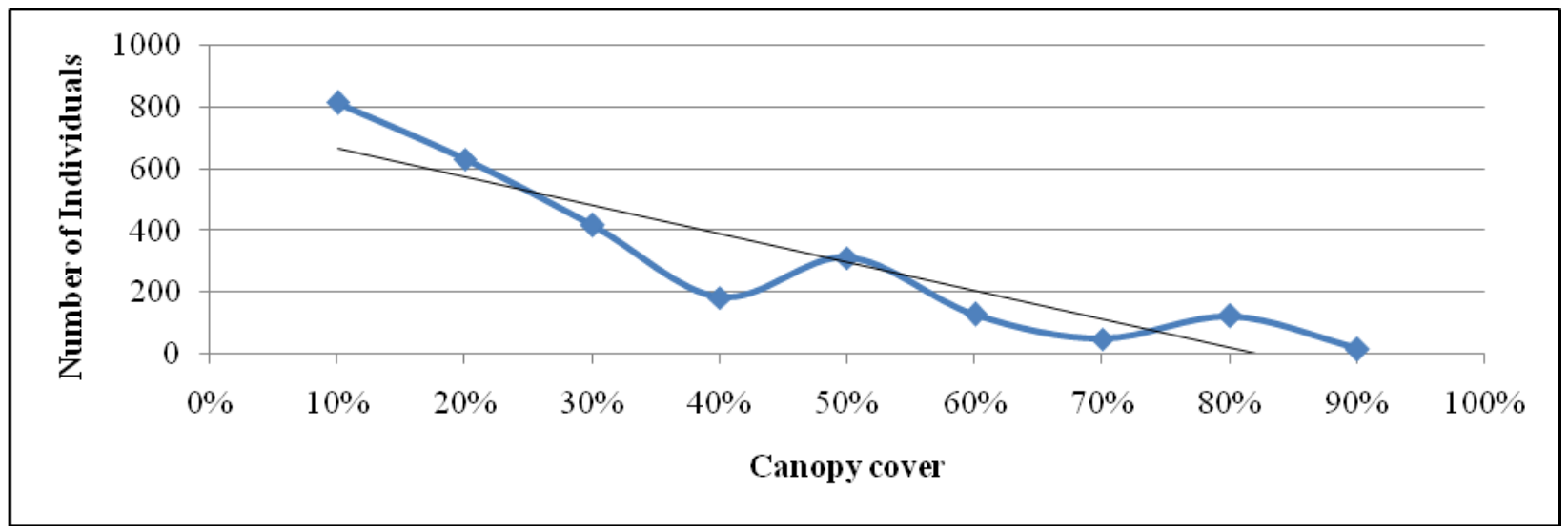

Figure 2: Variation of recorded number of butterfly individuals with canopy cover.

More adult feeding plants were found in the regenerating forest, which had less canopy cover. Most of the understory herbs and shrubs were nectar resources for adult butterflies. Most of the butterflies frequently fed on plant species such as Lantana camera, Stachytarpheta sp. and Eupatorium $s p$. Butterflies tend to feed on flowers of tree species in the flowering season. (i.e., Homalanthus populifolius, Vitex pinnata, Cassia siamea and Grewia damine). Most of herbs and shrubs in understory showed seasonal growth. After the rain these plants grow and blossom. In the dry season 
these plants dry up. There was a strong negative correlation between canopy cover and butterfly recordings. Both recorded number of individuals and number of species decreased with the canopy cover, but recorded number of species increased with number of individuals $(r=0.81)$ (Table 1).

Table 1: Pearson correlation coefficient values between abundance and number of species with canopy cover.

\begin{tabular}{lcc}
\hline & Canopy cover & Number of individuals \\
\hline Number of individuals & -0.91 & \\
Number of species & -0.85 & 0.81 \\
\hline
\end{tabular}

There is a significant difference of recorded abundance between each shade level $(\mathrm{p}<0.05)$. Furthermore, recorded number of species were significantly differed in each canopy cover level $(\mathrm{p}<0.001)$ (Table 2).

Table 2: Comparison of abundance and number of species with canopy cover using ANOVA test.

\begin{tabular}{lcccccccccccc}
\hline & \multicolumn{10}{c}{ Canopy cover } & & \\
\cline { 2 - 11 } & $10 \%$ & $20 \%$ & $30 \%$ & $40 \%$ & $50 \%$ & $60 \%$ & $70 \%$ & $80 \%$ & $90 \%$ & $\mathrm{~F}$ & $\mathrm{p}$ \\
\hline Number of & 816 & 632 & 417 & 184 & 313 & 128 & 50 & 124 & 17 & 10.49 & 0.005 \\
individuals & 47 & 61 & 55 & 36 & 45 & 33 & 21 & 34 & 13 & 54.05 & 0.000 \\
\hline
\end{tabular}

All butterfly families (except Hespiiridae and Riodinidae) showed the highest relative abundance at low canopy cover. Moreover, Papilionid butterflies were more abundant in moderately sunny areas. Species of family Hesperiidae preferred moderate shade conditions while family Riodinidae mainly recorded in all conditions (Table 3). Most of the butterflies preferred the sunny conditions, although some preferred shade conditions (i.e., Common evening brown-Melanitis leda, Plain tiger-Danaus chrysippus). Species with more than ten records were used to produce a box and whiskers plot. According to mean canopy cover of their presence few low shade specialists were found. They were mostly found in more sunny areas, but there were some outlying recordings. Most of the butterfly species prefer moderate shade conditions (Figure 3).

Table 3: Relative abundance of each butterfly family at different canopy levels.

\begin{tabular}{ccrcrrr}
\hline \multirow{2}{*}{$\begin{array}{c}\text { Canopy } \\
\text { cover }\end{array}$} & \multicolumn{5}{c}{ Family } \\
\cline { 2 - 6 } & Hesperiidae & Lycanidae & Nymphalidae & Papilionidae & Pieridae & Riodinidae \\
\hline $10 \%$ & 12.63 & 37.57 & 43.54 & 19.21 & 27.31 & 25 \\
$20 \%$ & 18.95 & 19.54 & 23.13 & 26.60 & 21.24 & 0 \\
$30 \%$ & 20.00 & 14.04 & 12.59 & 14.78 & 17.11 & 0 \\
$40 \%$ & 13.68 & 6.26 & 5.68 & 4.43 & 7.28 & 0 \\
$50 \%$ & 25.26 & 12.71 & 7.24 & 11.82 & 13.23 & 25 \\
$60 \%$ & 3.16 & 2.85 & 2.96 & 10.34 & 6.43 & 0 \\
$70 \%$ & 1.05 & 1.33 & 1.48 & 3.94 & 1.82 & 25 \\
$80 \%$ & 3.16 & 4.93 & 3.05 & 7.39 & 5.10 & 25 \\
$90 \%$ & 2.11 & 0.76 & 0.33 & 1.48 & 0.49 & 0 \\
\hline
\end{tabular}




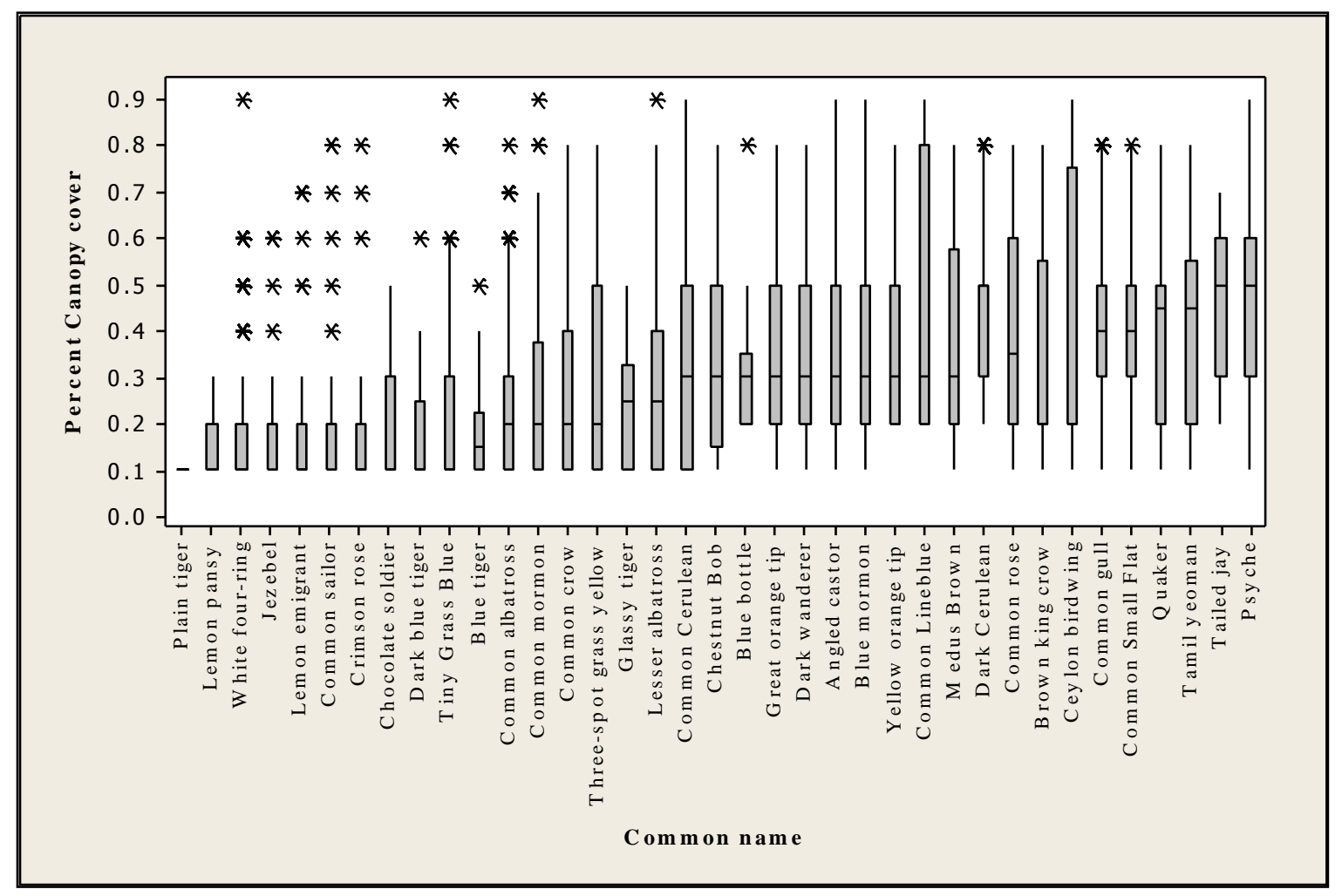

Figure 3: Distribution of each butterfly species with canopy cover\%. (note: graph containing butterfly species recorded more than ten times)

\section{Discussion}

Small herbs and shrubs grow faster and bloom in a short time period. Most of these plants are seasonal. Flowers of these herbs and shrubs provide nectar for adult butterflies for their energy requirement. Regenerating forest hosts many seasonal herbs and shrubs than natural forest. Therefore, it provides more floral nectar yield for butterflies than the natural forest. Lantana camera, Eupatorium sp. are some invasive shrubs that commonly found in regenerating area. These plants have more flowers than native plants. Therefore, these plants pollinate via nectar feeding insects such as butterflies than other plants. Furthermore, petal color of these invasive plants may be attracting more butterflies.

Plants such as Lantana sp. contain several colors of flowers. Thus, these flowers can gather many butterfly species. In terms of nutrients, the main energy source of adult butterflies is floral nectar. Hence, nectar is the primary energy source, butterflies assemble where flowers present. Canopy cover decreases radiation penetration to forest ground layer. Solar radiation is the energy for plant photosynthesis. Therefore, shaded areas lack a rich understory. Understory consists with many flowering plants which contain sweet nectar. These plants can attract many butterfly species. Therefore, these areas support rich butterfly abundance.

Butterfly abundance and species richness decreased with the canopy cover. However, slight amplified abundance and richness was observed around 50\% shade area. Most areas had 50\% canopy cover. Highest shade level in regenerating forest was $50 \%$ and young secondary forest had noticeable $50 \%$ shade areas. Hence, decreasing pattern of abundance and species richness was altered. At $80 \%$ shade, another increased abundance and species richness was recorded. This was due to the shade 
preferring butterflies. Few butterfly species were shade preferring and they were confined to mature parts of the young secondary forest. Presence of these butterfly species affected the abundance pattern and small increase in abundance and richness recorded (Figure1 and 2).

Since butterflies are ectothermic organisms their activity is basically depend on environment temperature. Basking is the basic adaptation of butterflies for their thermoregulation. Butterflies select a suitable substrate to rest and adjust their wings to reflect maximum solar radiation on their thorax. Therefore, most of the butterflies prefer the sunny conditions than shady conditions. However, a few butterfly species prefer shade and these butterflies have dark wing colors to increase the absorbance of solar radiation. More solar radiation increases the environmental temperature and decreases relative humidity. Most of the butterfly species prefer conditions with moderate relative humidity. Butterflies tend to rest at very low and very high relative humidity conditions. Therefore, highest number of species was recorded at moderate canopy cover.

Regenerating forests were the early stages in forest succession. During succession process young secondary forests will replace regenerating forest. Mature secondary forests could be observed following young secondary forests. Thus, regenerating forest adjoining to young secondary forest may provide good spectrum of canopy coverage. Regenerating forest had low canopy cover with more canopy gaps, while young secondary forest had more constant canopy. Therefore, findings of the study were applicable for any forest succession process.

\section{Conclusion}

Findings of the study highlight that more butterflies prefer sunny and moderately shady areas. However, some species restrict to more shady areas and these species are rare and found only in rich forest habitats. Therefore, forests should be preserved to protect these species from extinction.

\section{References}

Addai, G. and Baidoo P.K. 2013. The effects of forest destruction on the abundance, species richness and diversity of butterflies in the Bosomkese Forest Reserve, BrongAhafo Region, Ghana. Journal of Applied Biosciences, 64: 4763-4772.

Banks, J. and Bank, J. 2014. A selection of the butterflies of Sri Lanka, $\left(3^{r d} e d\right)$, Pannipitiya.

Collinge, S.K., Prudic, K.L. and Oliver, J.C. 2003. Effects of Local Habitat Characteristics and Landscape Context on Grassland Butterfly Diversity. Conservation Biology, 17(1): 178-187.

D'Abrera, B. 1998. The butterflies of Ceylon, ( $\left(^{\text {st }} e d\right)$, D'Abrera, Colombo 8.

Hamer, K.C., Hill, J.K.,Benedick, S.,Mustaffa, N., Sherratt, T.N., Maryati, M. and Chey V.K. 2003. Ecology of butterflies in natural and selectively logged forests of northern Borneo: the importance of habitat heterogeneity. Journal of Applied Ecology, 40: 150-162.

Hill, J.K., Hamer, K.C., Lace, L.A. and Banham, W.M.T. 1995. Effects of selective logging on tropical forest butterflies on Buru, Indonesia. Journal of Applied Ecology, 32: 754-760.

Hill, J.K. 1999. Butterfly spatial distribution and habitat requirements in a tropical forest: impacts of selective logging. Journal of Applied Ecology, 36: 564-572.

Malabika, S.K. 2011. Impact of tropical forest degradation on nymphalid butterflies: A case study in Chandubi tropical forest, Assam, India. International Journal of Biodiversity and Conservation, 3(12): 650-669.

Spitzer, K., Novotny, V., Tonner, M. and Leps, J. 1993. Habitat preferences, distribution and seasonality of the butterflies (Lepidoptera, Papilionoidea) in a montane tropical rain forest, Vietnam. Journal of Biogeography, 20: 109-121. 